\title{
The Simulation Investigation of RP-3 Aviation Kerosene Ignition Characteristics
}

\author{
Lei Shi*, Yubin Men and Jia Cheng \\ Aero Engine Corporation of China, Shenyang Engine Research Institute, Shenyang, China \\ *Corresponding author
}

Keywords: RP-3 aviation kerosene, Ignition characteristics, Reaction mechanisms, Active particles.

\begin{abstract}
The fast ignition and stable combustion of fuel is a very important problem in designing gas turbine combustor. In this paper, the detailed fuel reaction process and primary influence factors for ignition delay time were studied by the chemical kinetic mechanisms. The chemical kinetic mechanisms of RP-3 aviation kerosene was put forward by analyzing its alternative fuel consisted of $80 \%$ decane and 20\% 1,2,4-trimethylbenzene(volume fraction). The results show that the ignition process of RP-3 aviation kerosene was divided two phases, the first phase is macromolecular oxidized slowly, the second phase is small molecules reacted strongly. The primary influence factors for ignition delay time are initial air temperature and the concentration of $\mathrm{OH}, \mathrm{O}$ and $\mathrm{H}$, and the effect extent of three particles was $\mathrm{H}, \mathrm{O}$ and $\mathrm{OH}$ in turn.
\end{abstract}

\section{Chemical Kinetic Mechanisms}

RP-3 aviation kerosene is primary fuel for gas turbine combustor in our country. It is one kind of hydrocarbon fuel consisted of 92.1\% saturated hydrocarbon and 7.9\% aromatic compounds (volume fraction). The physical and chemical characteristics of RP-3 aviation kerosene[1] are similar to Jet-A aviation kerosene[2] aboard, so the chemical kinetic mechanisms model of RP-3 aviation kerosene can be put forward by analyzing Jet-A aviation kerosene mechanisms model. By comparison with different kinds of Jet-A aviation kerosene alternative fuel, the alternative fuel proposed by Honnet consisted of $80 \%$ decane and 20\% 1,2,4-trimethylbenzene(volume fraction)[3] is chosen as the alternative fuel for RP-3 aviation kerosene. Then the chemical kinetic mechanisms model of the alternative fuel come to be the mechanisms model of RP-3 aviation kerosene. In order to consider the NOx formation in combustion, the NOx mechanisms model[4] proposed by Hewson and Bollig is added to mechanisms model of RP-3 aviation kerosene. After that, one mechanisms model including 131 species and 1020 reactions is put forward, which is called Honnet model. The scope of application of the mechanisms model is 700 3000K and 1 25atm. The ignition delay time and laminar flame speed are calculated by Honnet model in different conditions, the prediction of the model agree well with experiment data[5], look figure1 and figure2. In conclusion, the alternative fuel model for RP-3 aviation kerosene is correct.

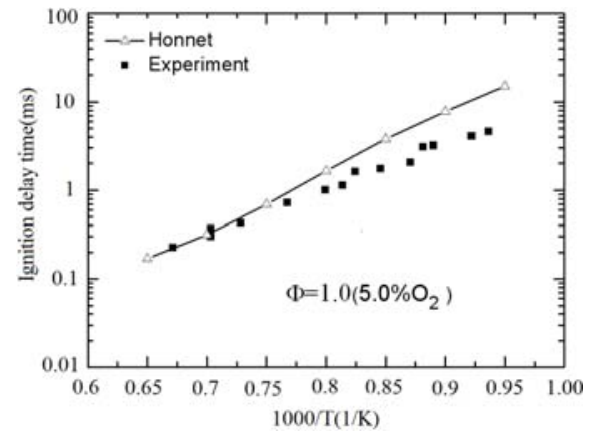

(a)

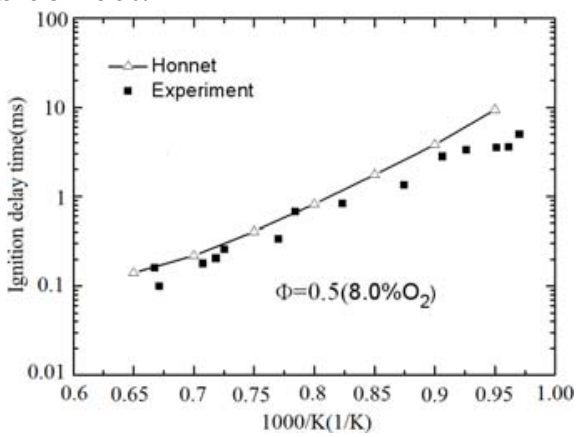

(b)

Figure 1. The comparison of delay time between experimental data and simulation 


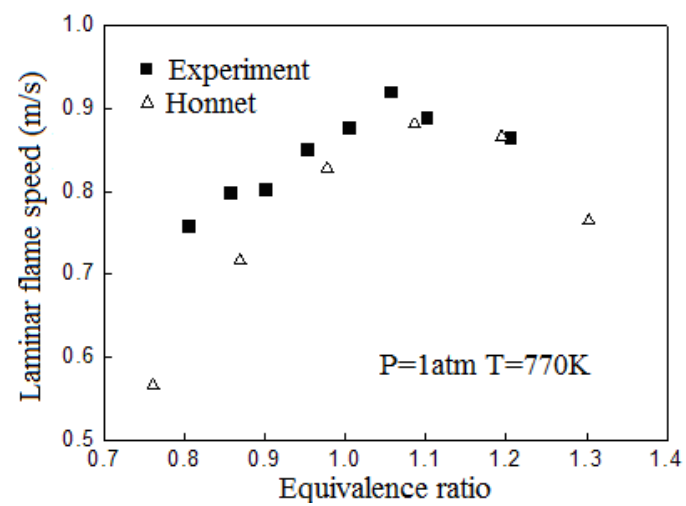

Figure 2. The comparison of laminar flame speed between experimental data and simulation[6]

\section{Fuel Dissociation}

The closed reactor model in CHEMKIN is used to simulate the RP-3 aviation kerosene combustion. In reactor, the initial temperature is $849 \mathrm{~K}$, initial pressure is $2000 \mathrm{kPa}$, residence time is $0.01 \mathrm{~s}$, the gas mixture is consisted of decane, 1,2,4-trimethylbenzene, air and argon in a certain ratio. The time which the inflexion temperature appears is usually the fuel ignition time in theory, as a contrast, the time which the $\mathrm{OH}$ peak concentration appears is the fuel ignition time in experiment. The time interval from starting ignition to fuel combustion is called ignition delay time. Figure3 and Figure4 are burnt gas temperature and active particles concentration variation trend by reaction time. The ignition delay time is $3.3 \mathrm{~ms}$ by analyzing the two figures.



Figure 3. The burnt gas temperature variation trend



Figure 4. The active particles concentration variation trend

The molecular formula of alternative fuel is defined as NXC10H22 because decane takes a great proportion in alternative fuel. The reaction path analysis method is used to research the dissociation of NXC10H22 in ignition delay time. The results show that the whole ignition delay time is divided into two phases by primary reaction path, the time interval and reaction equations are different. Look at Table1. In the first phase, the burnt gas temperature rises slightly, the macromolecules 
NXC10H22 turn into small molecules C2H3 by 6 main reaction paths. The cracking process of $\mathrm{NXC10H} 22$ is very slow because of lack of active particles in early stage, takes $85 \%$ of ignition delay time. The burnt gas temperature and the concentration of $\mathrm{OH}, \mathrm{O}$ and $\mathrm{H}$ rise slowly as the reaction goes on, to support energy and active particles for later reaction. In a word, the first phase is the macromolecules turn into small molecules. And the cracking process of NXC10H22 is the oxidation of $\mathrm{C} 10 \mathrm{H} 21 \mathrm{O} 2$ by analyzing the reaction path map.

In the second phase, the reaction energy and the concentration of active particles have got a certain level because of early reactions, so the reactions between small molecules are very intense. As a result, the burnt gas temperature and the concentration of $\mathrm{OH}$ and $\mathrm{O}$ rise sharply, the concentration of $\mathrm{H}$ rises slightly. After that, the ignition process finishes and the reaction continues to stable stage, the burnt gas temperature does not change and the $\mathrm{O}$ and $\mathrm{H}$ are exhausted, the concentration of $\mathrm{OH}$ come to be a low level.

Table 1. The ignition performance of RP-3 aviation kerosene

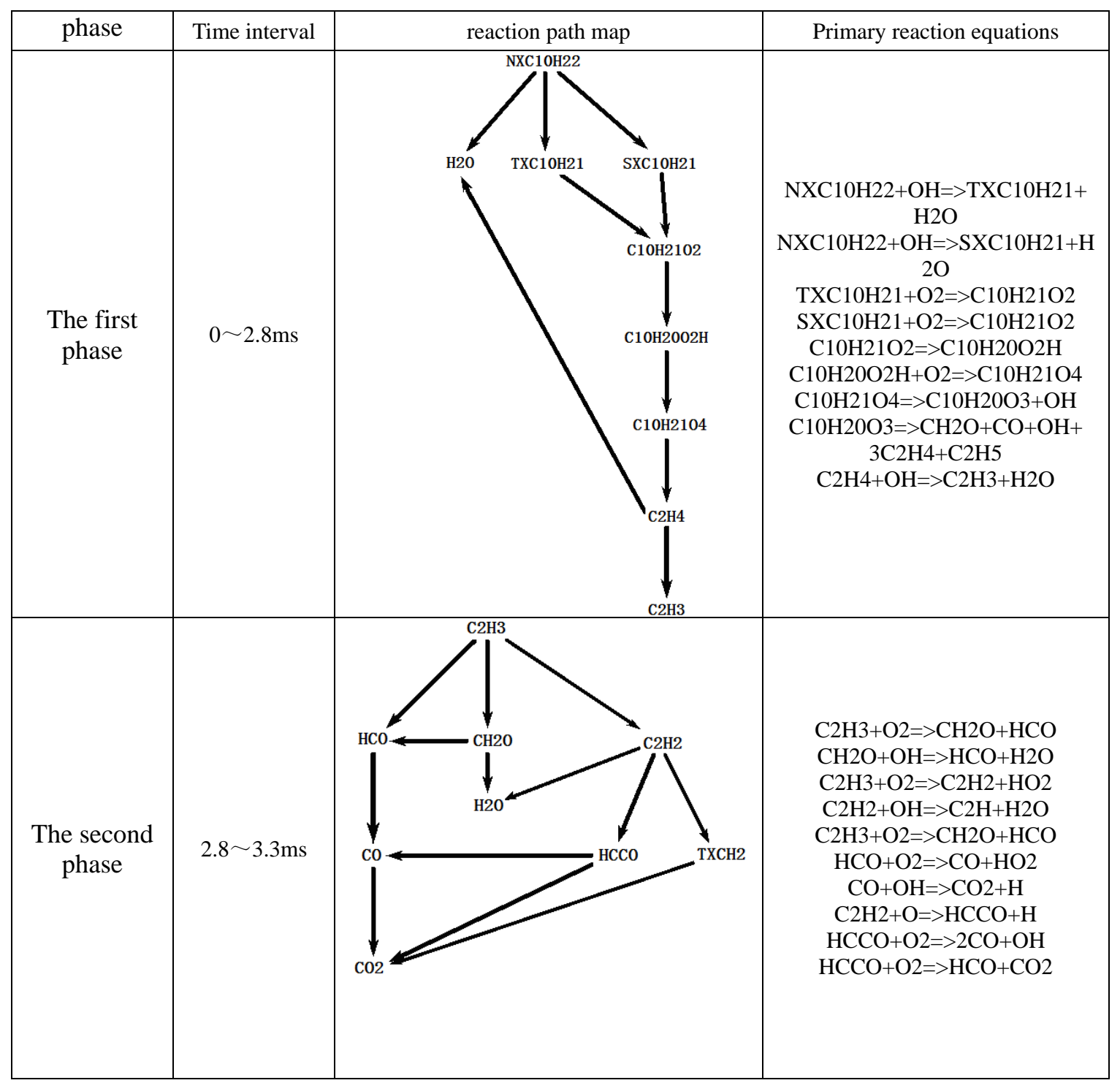

\section{Influence Factors Analysis}

Based on Arrhenius equation $k=A e^{-\frac{E_{a}}{R T}}$, the higher the fuel temperature is, the faster the reaction rate is. After that, the active particles' influence for ignition delay time is studied in this paper. It is known that the active particles playing a important role in ignition process refer $\mathrm{OH}, \mathrm{O}$ and $\mathrm{H}$ primary for early research. The fuel combustion is simulated when the mass fraction of the active 
particles is $0.05 \%, 0.1 \%$ and $0.5 \%$ in fuel to study the influence of active particles for ignition delay time. Look at Figure 5, the ignition delay time shorten significantly as the increase of the mass fractions of active particles. And the burnt gas temperature will increase if the mass fraction of the particles exceed a certain level. Look at Figure 6, at the same mass fraction of active particles, the ignition delay time is shortest for the fuel added $\mathrm{H}$, shorter for the fuel added $\mathrm{O}$ and short for the fuel added $\mathrm{OH}$. In a conclusion, the influence degree of each active particles on ignition is $\mathrm{H}, \mathrm{O}$ and $\mathrm{OH}$.

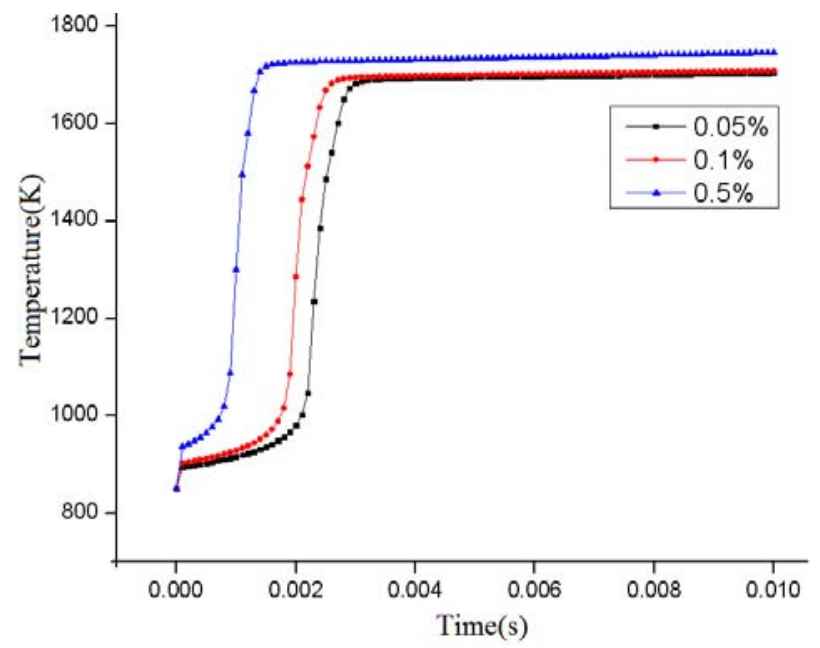

(1) The concentration variation trend of $\mathrm{OH}$

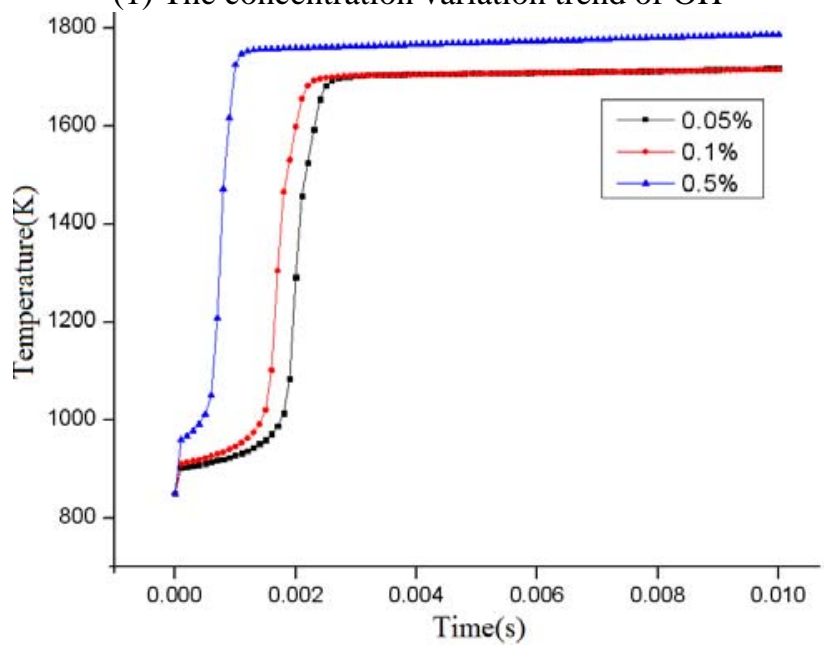

(2) The concentration variation trend of $\mathrm{O}$

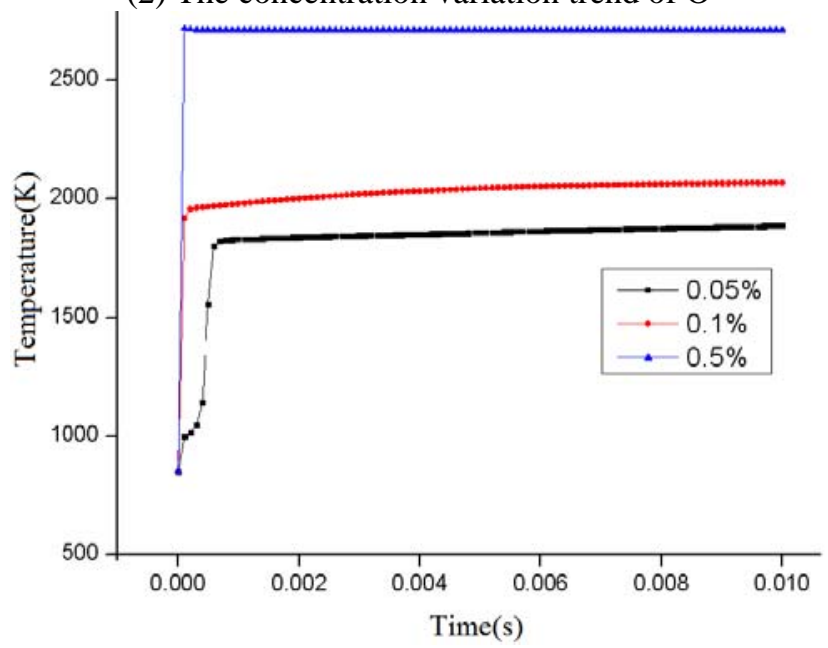

(3) The concentration variation trend of $\mathrm{H}$

Figure 5. The correlation between the concentration of active particles and ignition delay time 


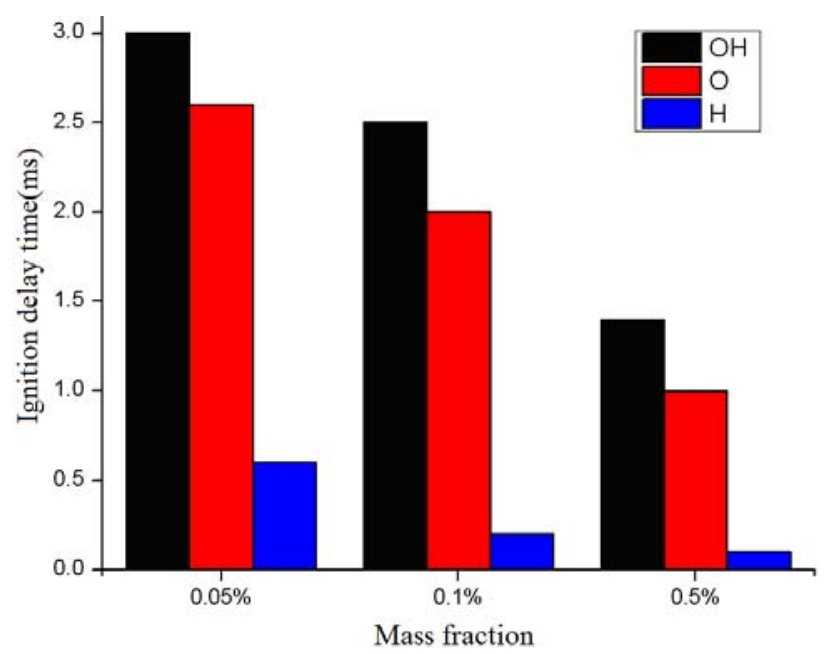

Figure 6. The ignition delay time for different active particles at the same concentration

\section{Conclusion}

1. The ignition process of RP-3 aviation kerosene was divided two phases, the first phase is macromolecular oxidized slowly, which accounts for $85 \%$ of the ignition delay time, and the second phase is small molecules reacted strongly.

2. The main influence factors for the RP-3 ignition performance are initial temperature and the concentration of the active particles. The main active particles playing a key role on ignition are $\mathrm{H}, \mathrm{O}$ and $\mathrm{OH}$, and the influence degree of each active particles on ignition is $\mathrm{H}, \mathrm{O}$ and $\mathrm{OH}$.

\section{Reference}

[1] Ma Hongan, Xie Maozhao, Zeng Wen et al. Experimental study on combustion characteristics of Chinese RP-3 kerosene[J]. Chinese Journal of Aeronautics, 2016, 29(2): 375-385

[2] Dagaut P., Cathonnet M. The Ignition, Oxidation, and Combustion of Kerosene: A Review of Experimental and Kinetic Modeling[J]. Progress in Energy and Combustion Science, 2006, 32:48-92.

[3] Honnet S., Seshadri K., Niemann U., et al. A Surrogate Fuel for Kerosene [J]. Proceedings of the Combustion Institute, 2009, 32:485-492.

[4] Hewson J. C., Bollig M. Reduced Mechanism for NOx Emissions from Hydrocarbon Diffusion Flames[R]. Twenty-Sixth Symposium (International) on Combustion, 1996, 2171-2179.

[5] Wang S., Fan B. C., He Y. Z., et al. Shock Tube Study of Kerosene Ignition Delay[J]. Shock Waves, 2009, Part IX,775-780.

[6] Violi A, Yan S, Eddings E G, et al. Experimental formulation and kinetic model for JP-8 surrogate mixture. Combustion Science and Technology, 2002, 174:11-12. 